\title{
EXPLORING THE VARIABILITY OF THE VENUSIAN ATMOSPHERE ABOVE THE CLOUDS WITH THE IPSL VENUS GCM
}

S. Lebonnois (LMD/IPSL, Paris, France)

G. Gilli, D. Quirino, V. Silva (IA/FCUL, Lisbon, Portugal)

T. Navarro (McGill, Montreal, Canada)

F. Lefèvre, A. Määttänen (LATMOS/IPSL, Paris, France) 


\section{Observed variability above clouds}

\section{Venus-Express atmospheric drag experiment :}

- aerobraking => 130-140 km altitude density profiles

- torque => 165-190 km altitude density profiles

Gravity waves signatures, horizontal wavelengths in $100-300 \mathrm{~km}$ range

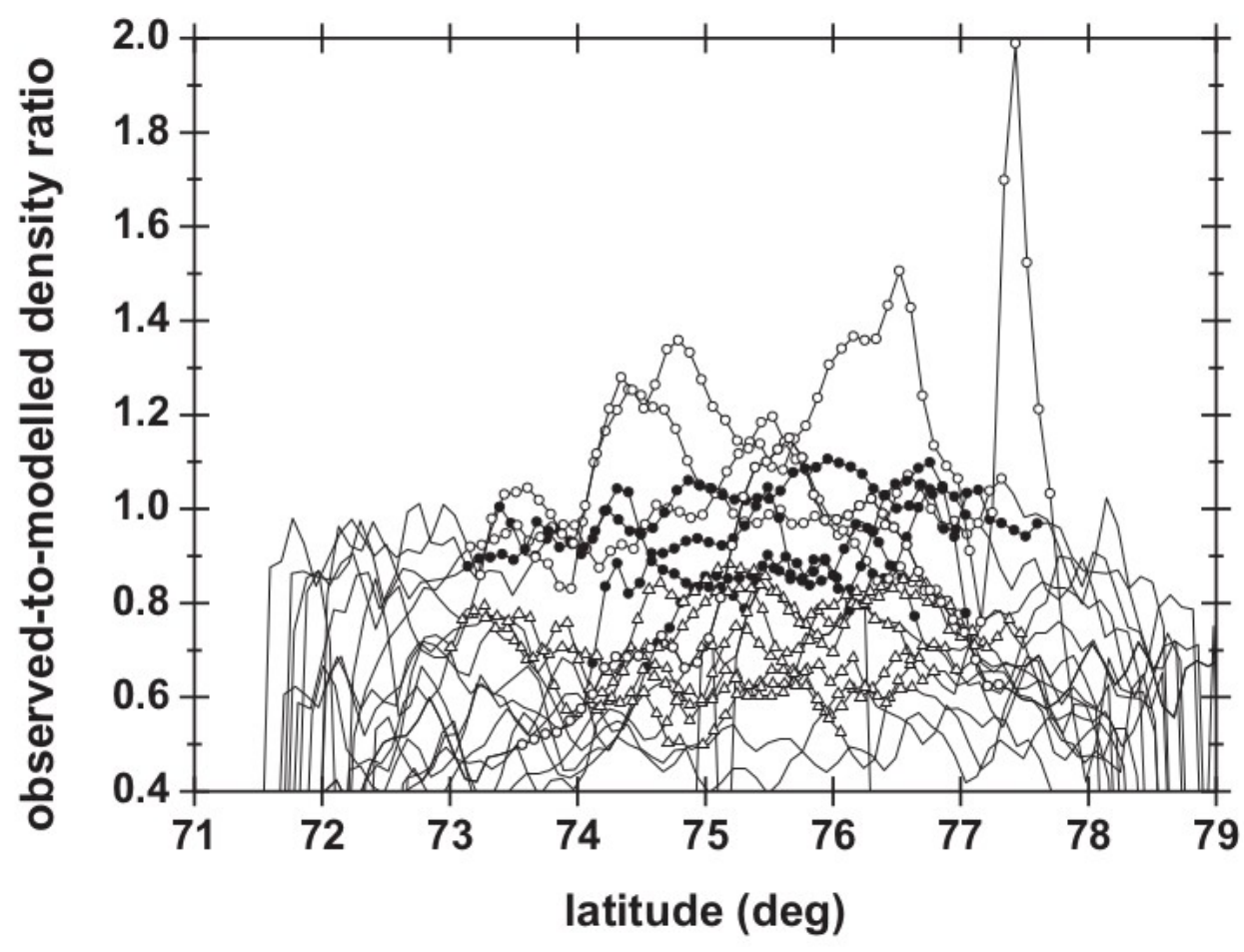

Müller-Wodarg et al., Nature Physics, 2016

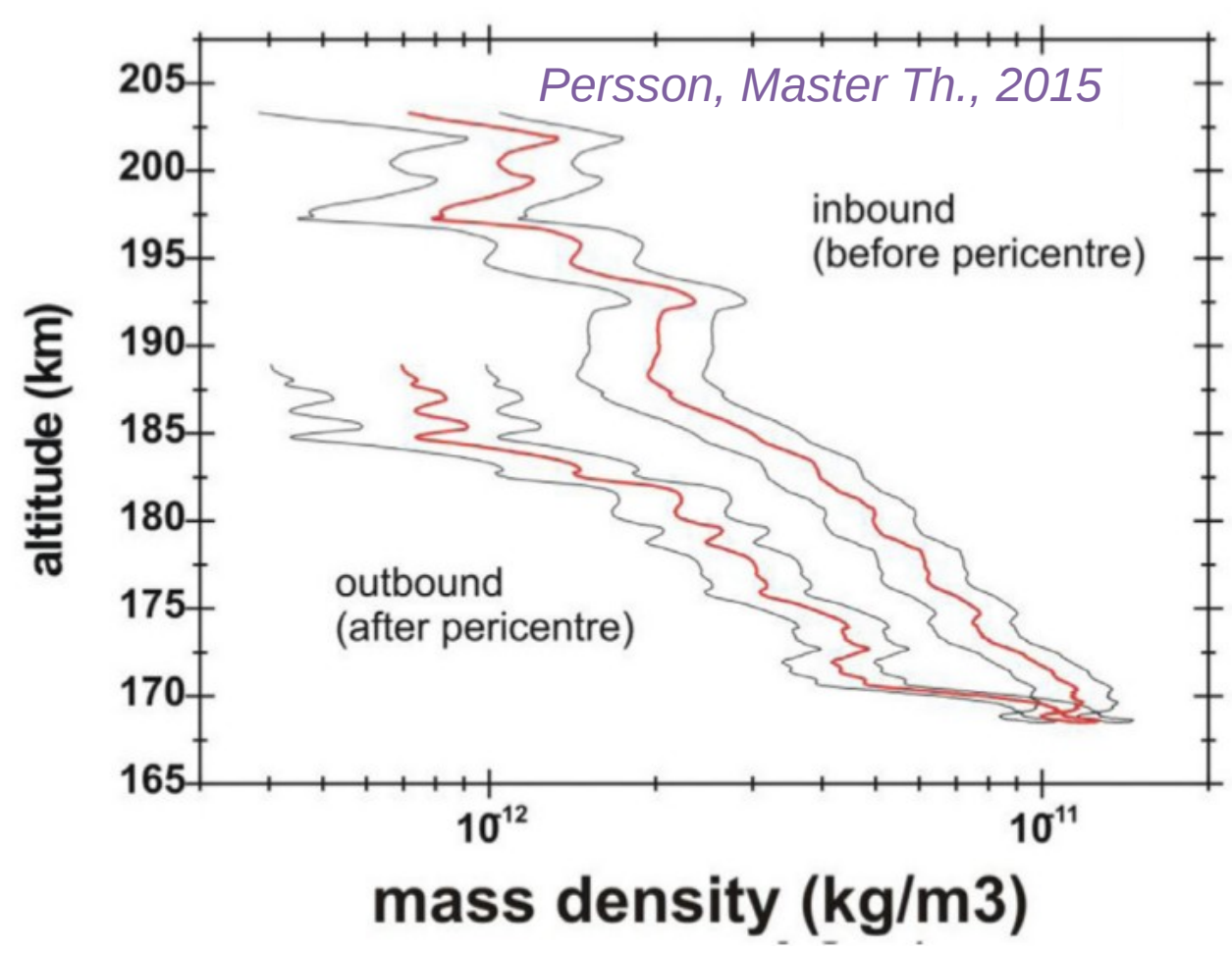

$85^{\circ} \mathrm{N}$, near terminator (inbound on dayside) 


\section{Observed variability above clouds}

Temperature measurements

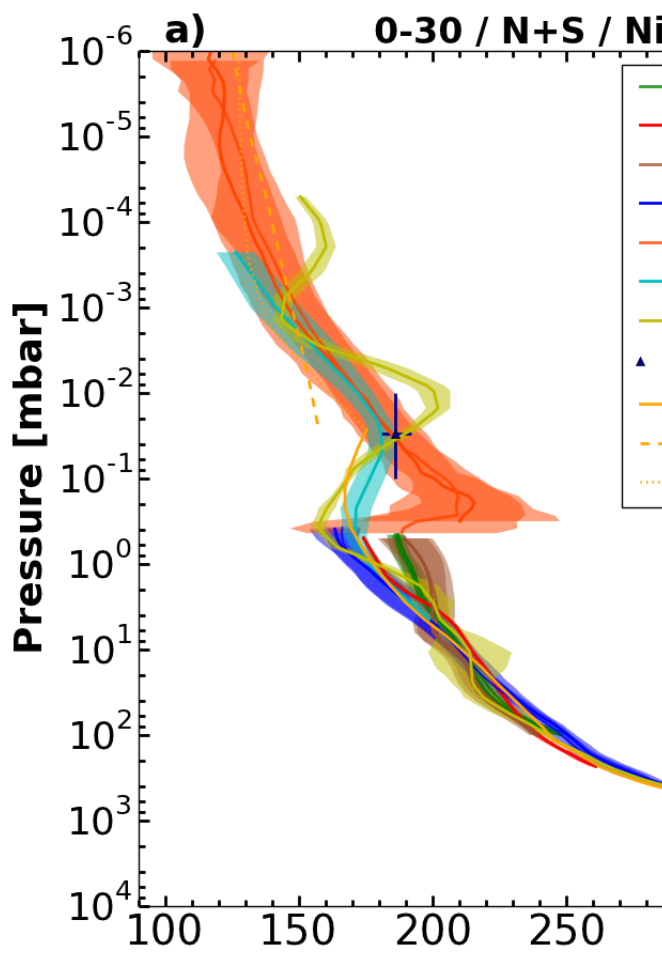

Temperature $(\mathrm{K})$

\section{NIGHT}

Limaye et al., Icarus 294, 2017

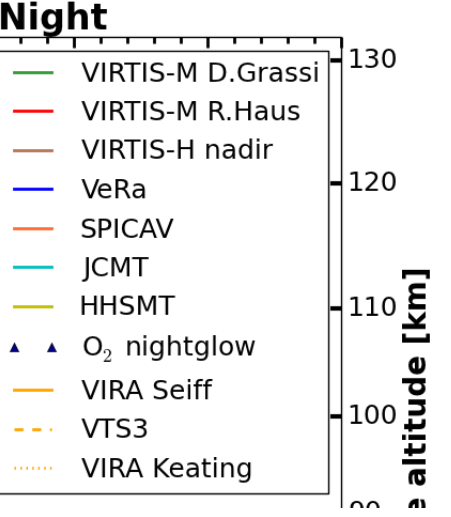

\section{$10^{-7}$ a) , 70-80 / N+S / Night}

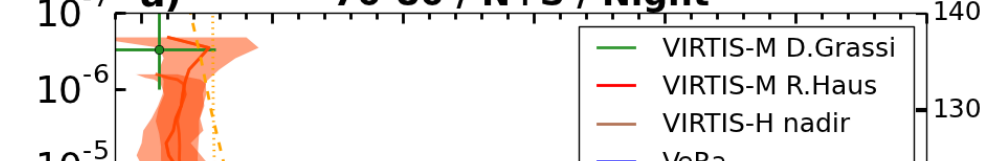

$10^{-5}$

$5^{10^{-4}}$

ह $10^{-3}$

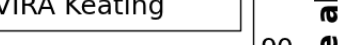

$10^{-6}$ a) $50-70 / \mathbf{N}+\mathbf{S} /$ Night,$\ldots$

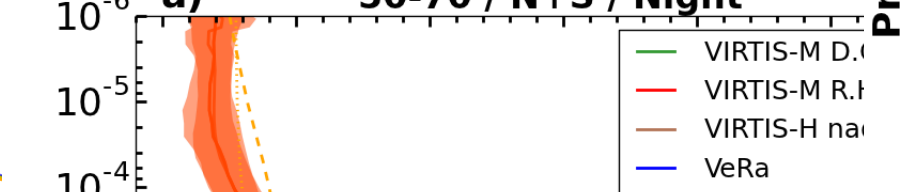

— VIRTIS-H na

- VeRa

- SPICAV

- Venera $15 \mathrm{R}$

究 ${ }^{10^{-3}}$

蛋 $10^{-2}$

ऐ $10^{-}$

पू 10

- Magellan

- JCMT

- VIRA Seiff

-. VTS3

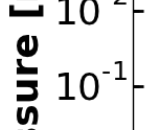

घे $10^{\circ}$

$10^{1}$

$10^{2}$

$10^{3}$

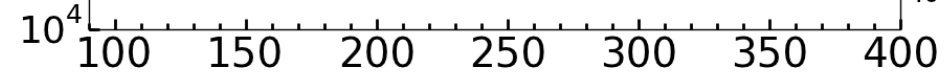

- VeRa

- SPICAV

- Venera 15 RO

- JCMT

- VIRA Seiff

-. VTS3

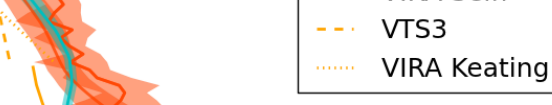

g

Temperature $(\mathrm{K})$

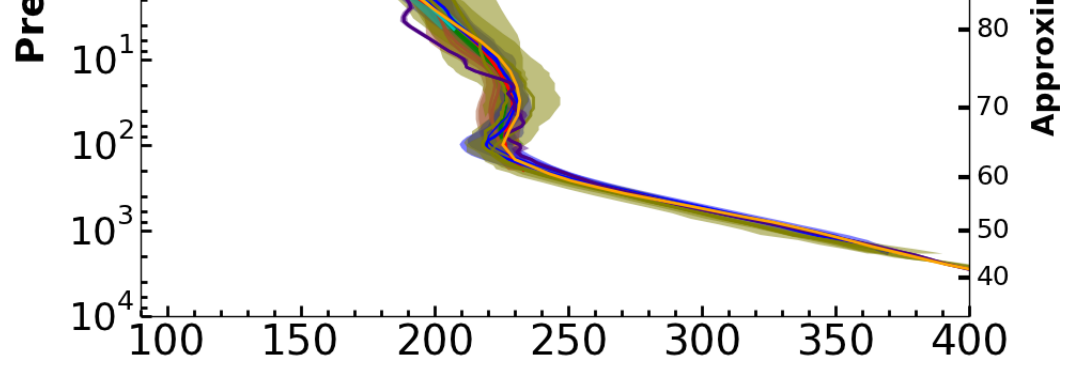




\section{Observed variability above clouds}

Temperature measurements

Limaye et al., Icarus 294, 2017

TERMINATORS

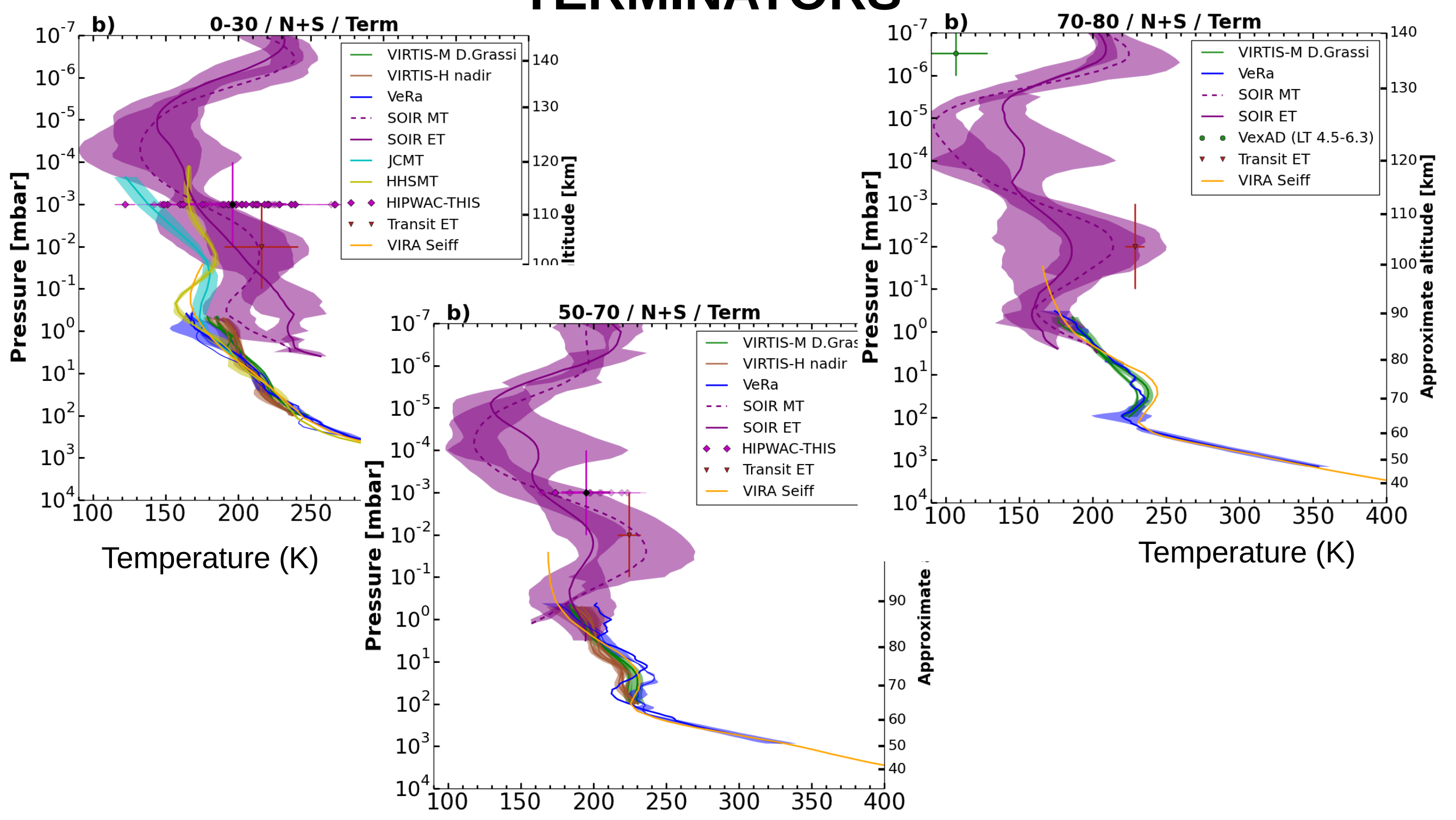




\section{Observed variability above clouds}

\section{Temperature measurements}

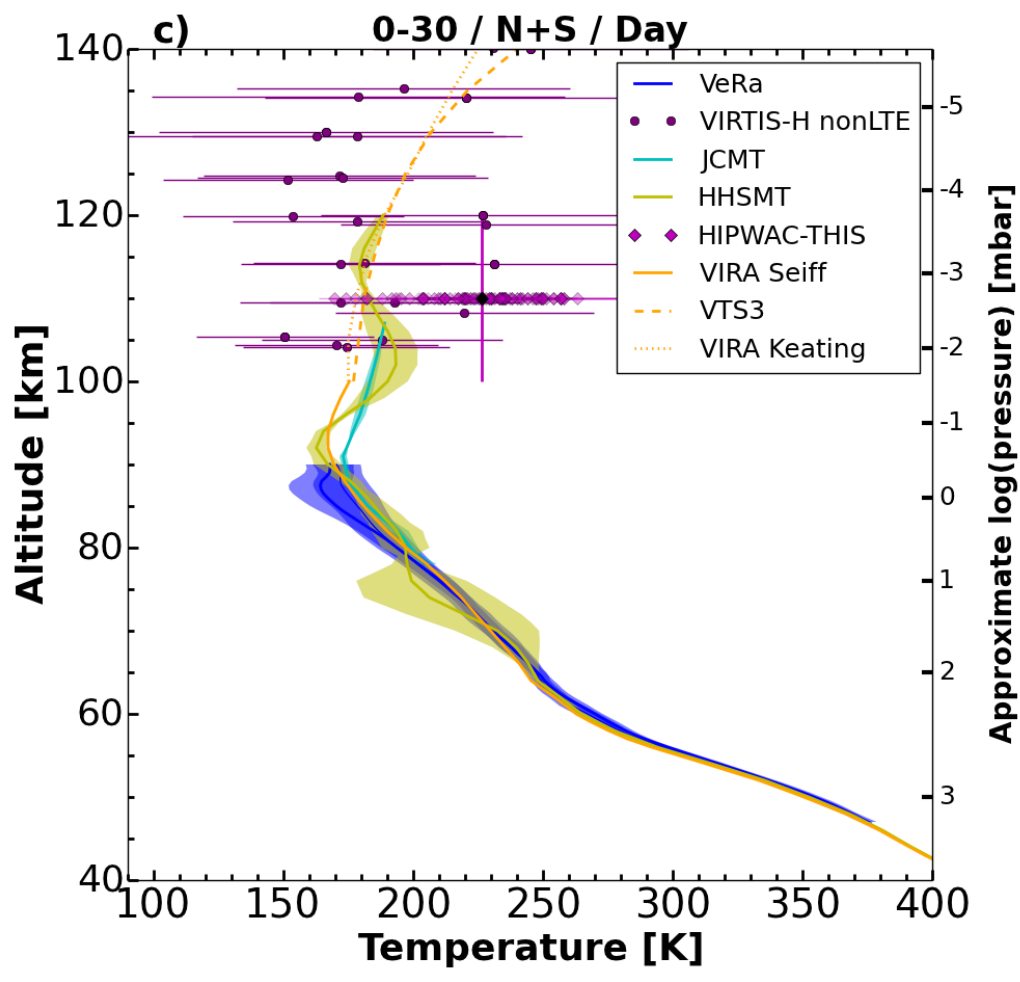

DAY

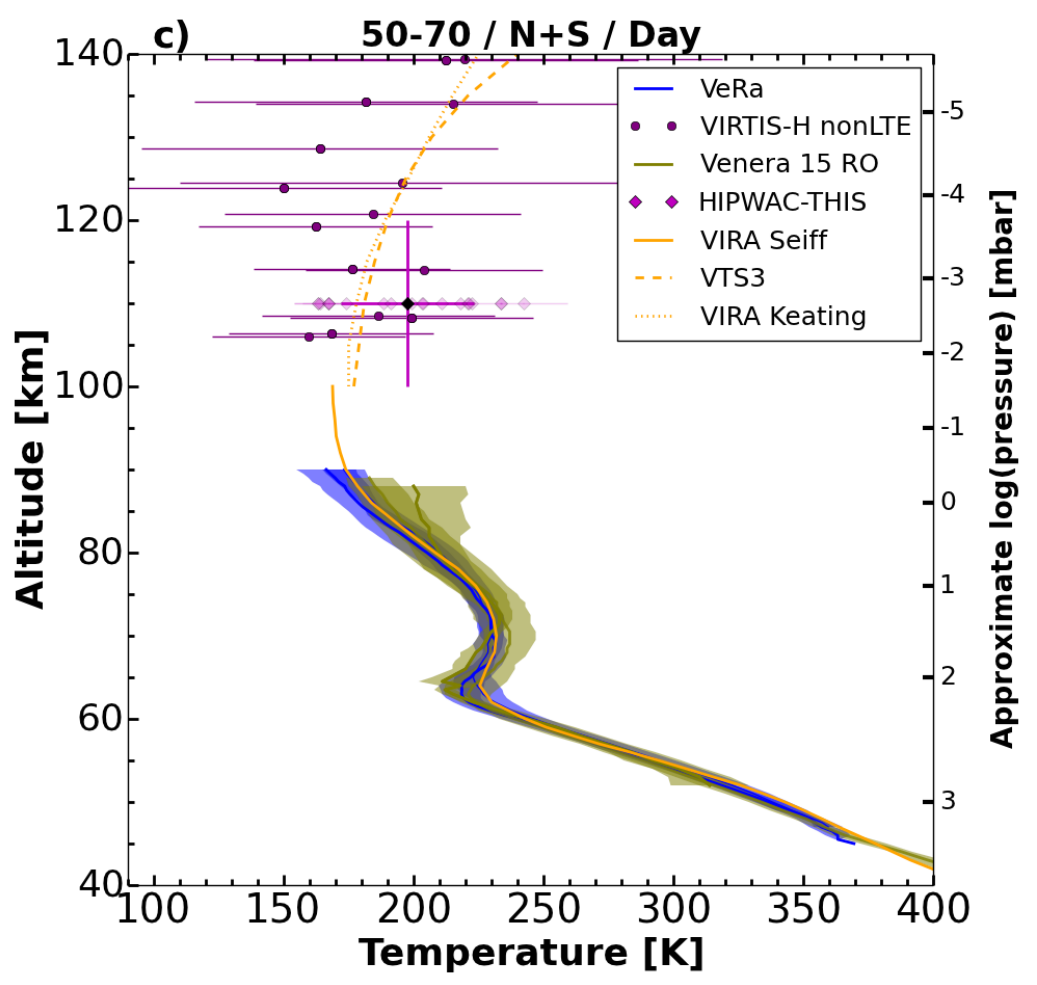




\section{Observed variability above clouds}
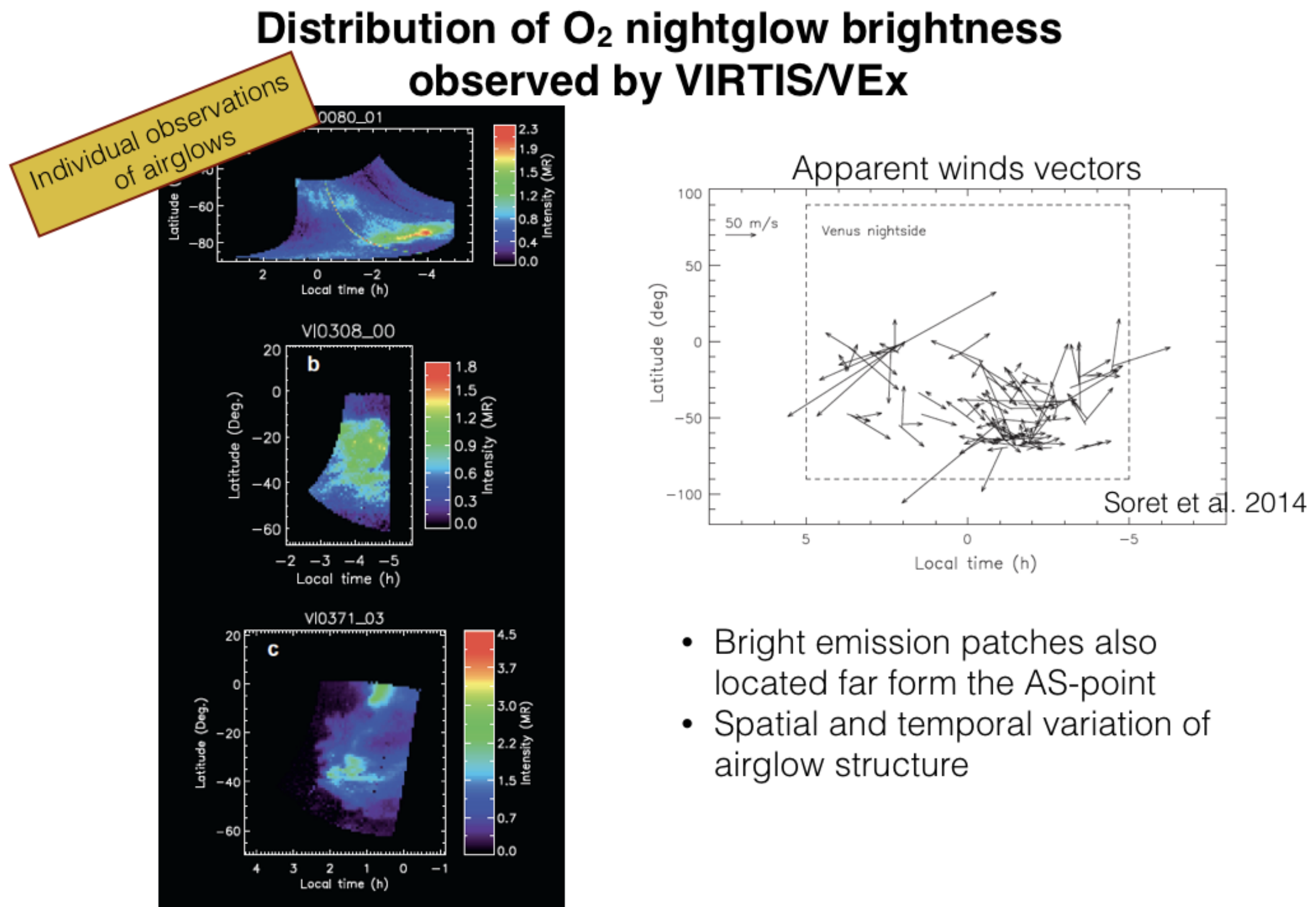

Soret et al. 2014 


\section{The IPSL Venus GCM}

- Three-dimensional: 96x96x78 (0 150 km)

- Vertical coordinates: hybrid (sigma/pressure)

- Dynamical core, transport of tracers

- Specific physics:

- Radiative transfer: Infrared Net Exchange Rates matrix Solar heating rates: tables

* Thermosphere: Non-LTE processes

EUV heating molecular diffusion

* Parameterizations of sub-grid processes: boundary layer (Mellor\&Yamada 1982), convection non-orographic gravity waves orographic gravity waves

* Topography

- Photochemistry implemented (PhD of Aurélien Stolzenbach)

Gilli et al (2017) ; Garate \& Lebonnois (2018) ; Navarro et al (2018) 


\section{The IPSL Venus GCM}

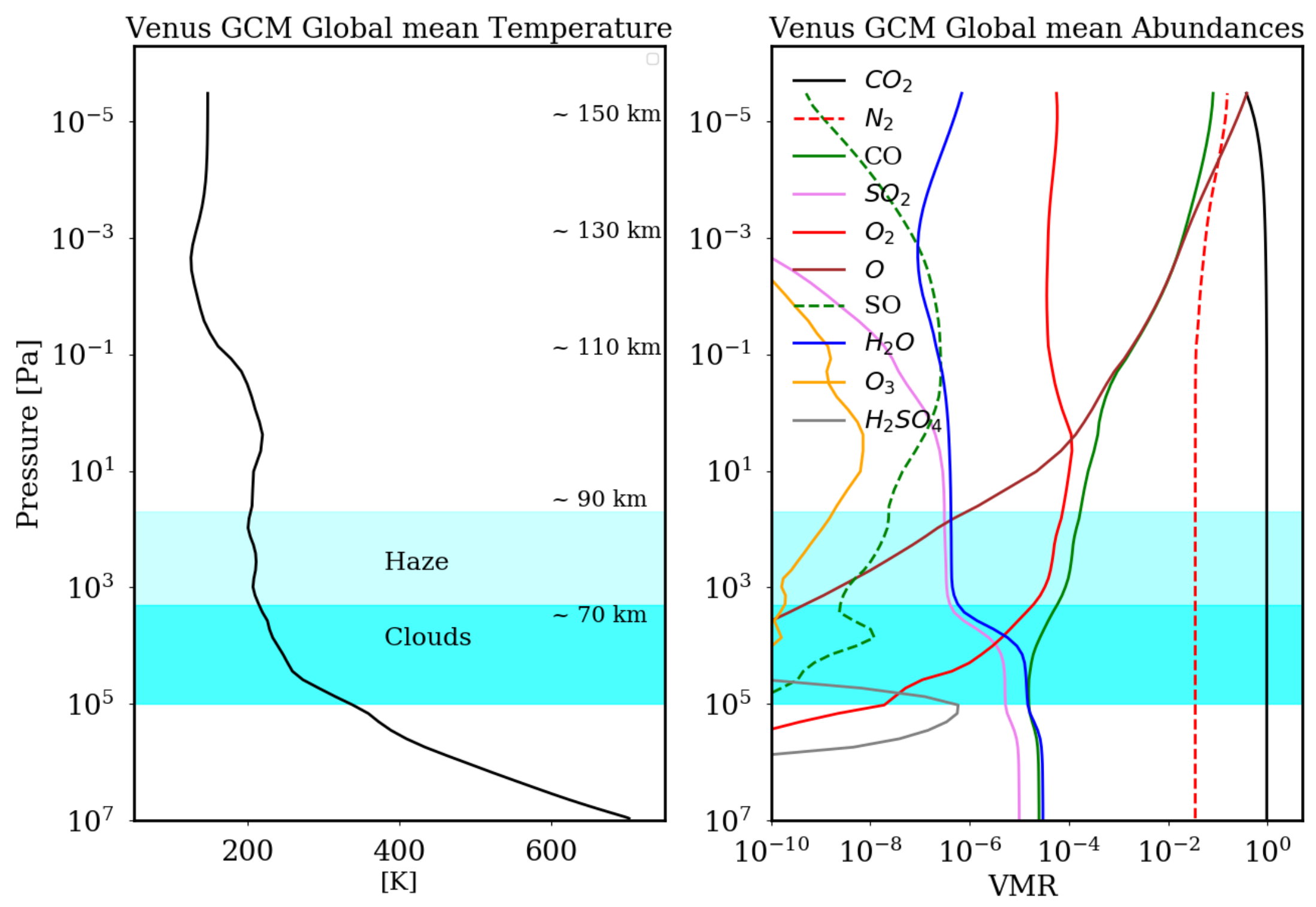




\section{Modeled densities and temperatures compared to observations}

\section{Density measurements}

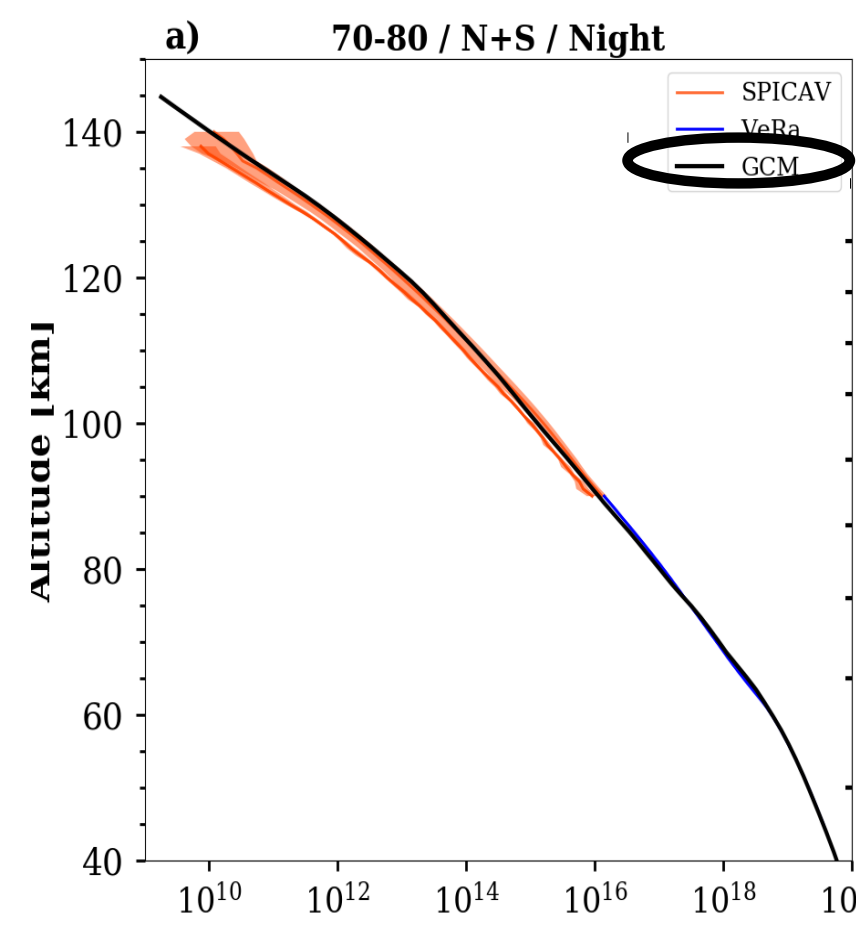

Lebonnois et al. D2903 - EGU2020-18583
Limaye et al., Icarus 294, 2017

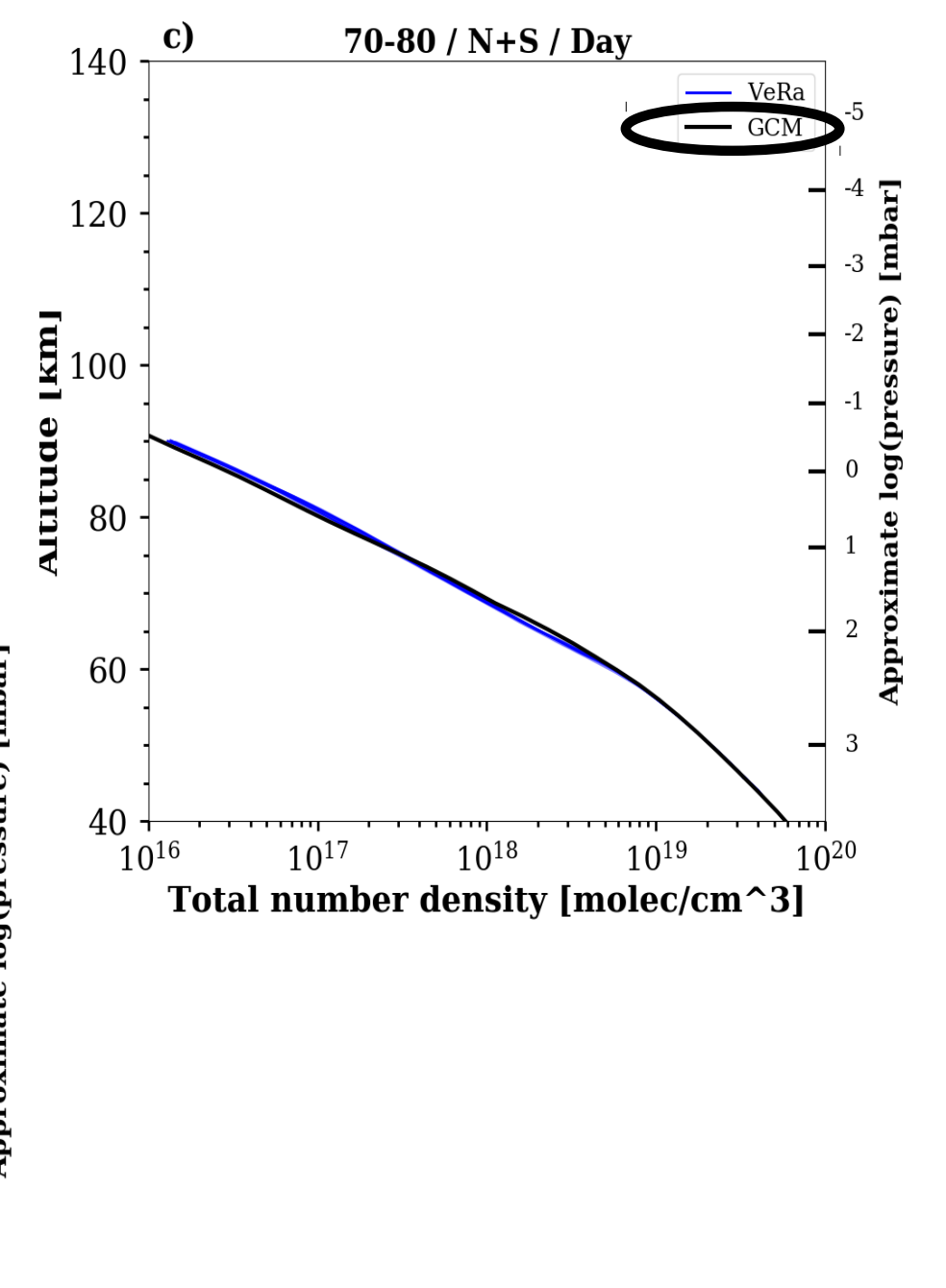




\section{Modeled densities and temperatures}

\section{compared to observations}

\section{Temperature measurements}

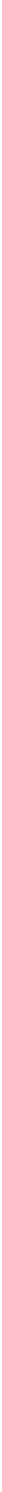




\section{Modeled densities and temperatures compared to observations}

\section{Temperature measurements}

\section{DAY}
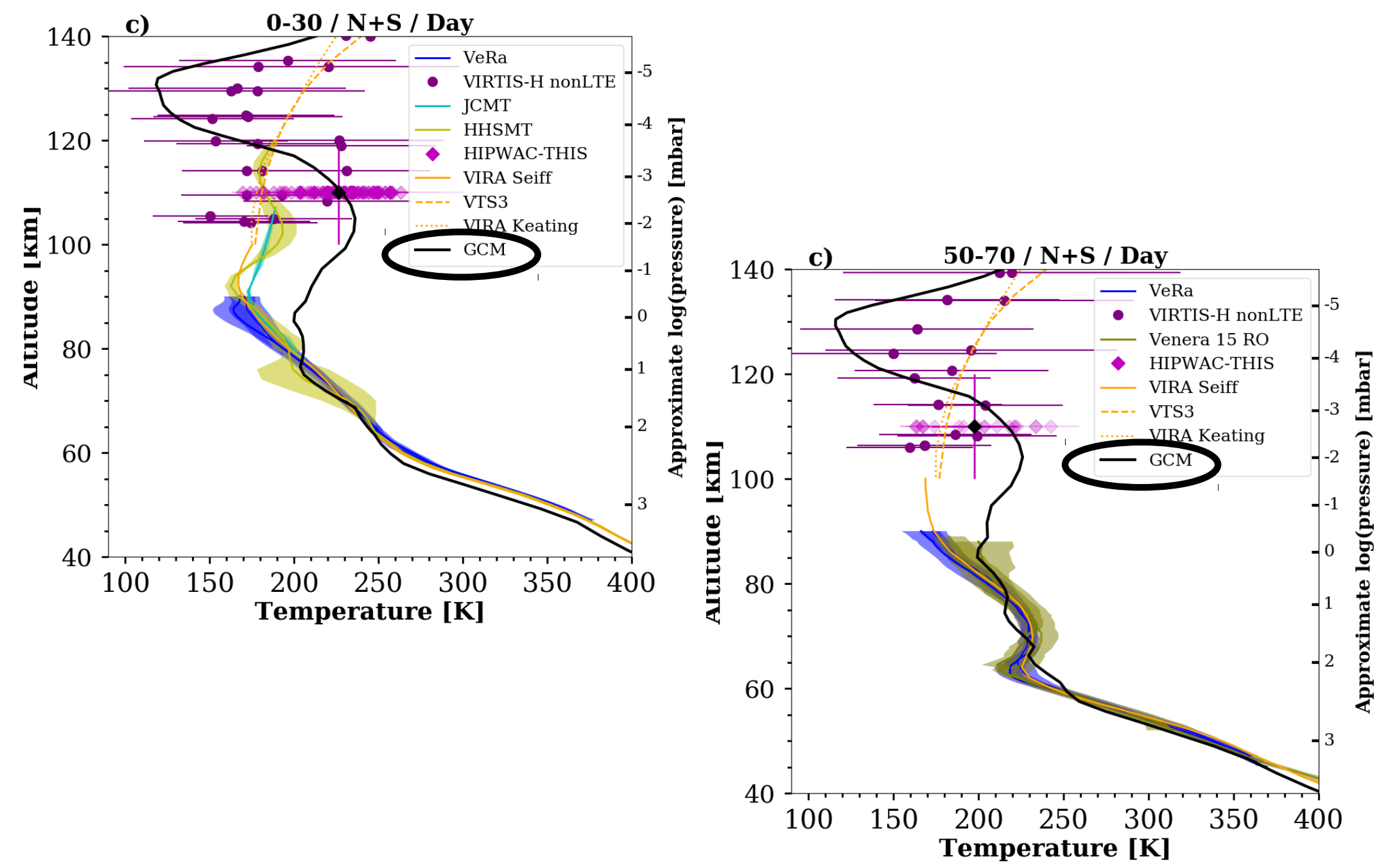


\section{Circulation variability}

Vertical wind (colors) and zonal wind (contours) at $1 \mathrm{~Pa}(\sim 105 \mathrm{~km})$

$$
\text { morning }
$$
terminator

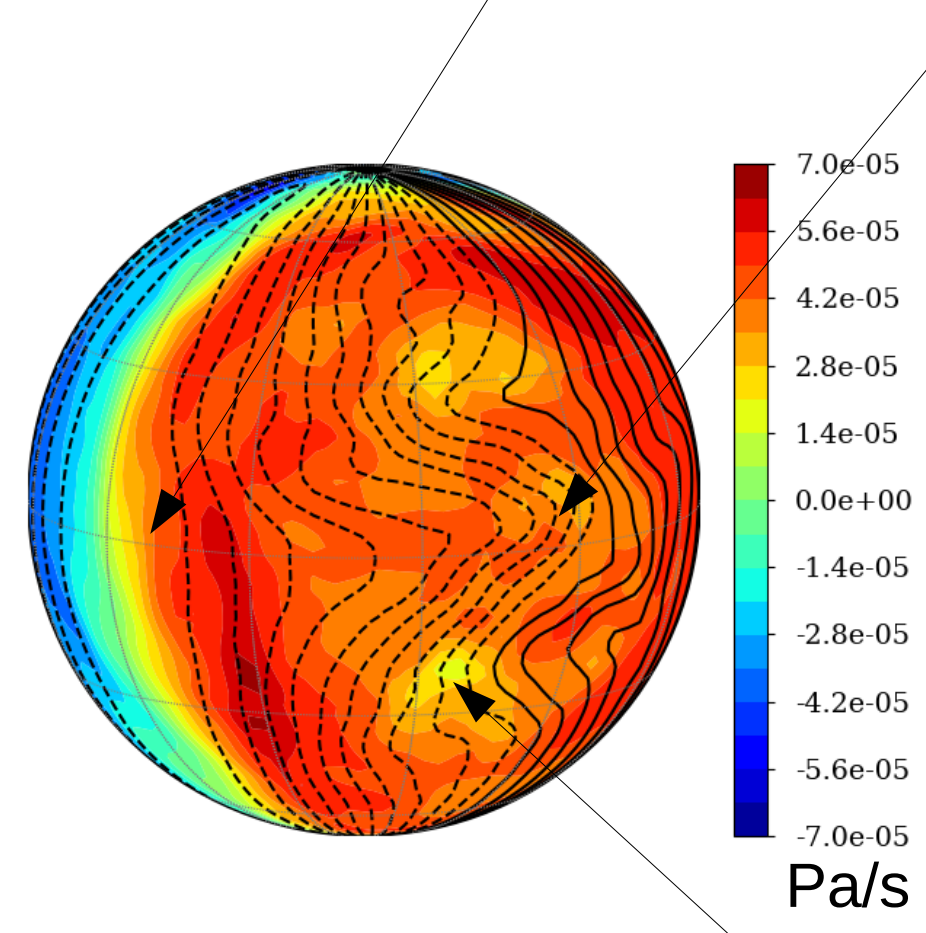

Oxygen nightglow (colors) and zonal wind (contours) at $10 \mathrm{~Pa}$ $(\sim 95 \mathrm{~km})$

Oxygen nightglow occurs in subsidences (positive vertical winds in $\mathrm{Pa} / \mathrm{s}$ ) 


\section{Non-orographic gravity waves}

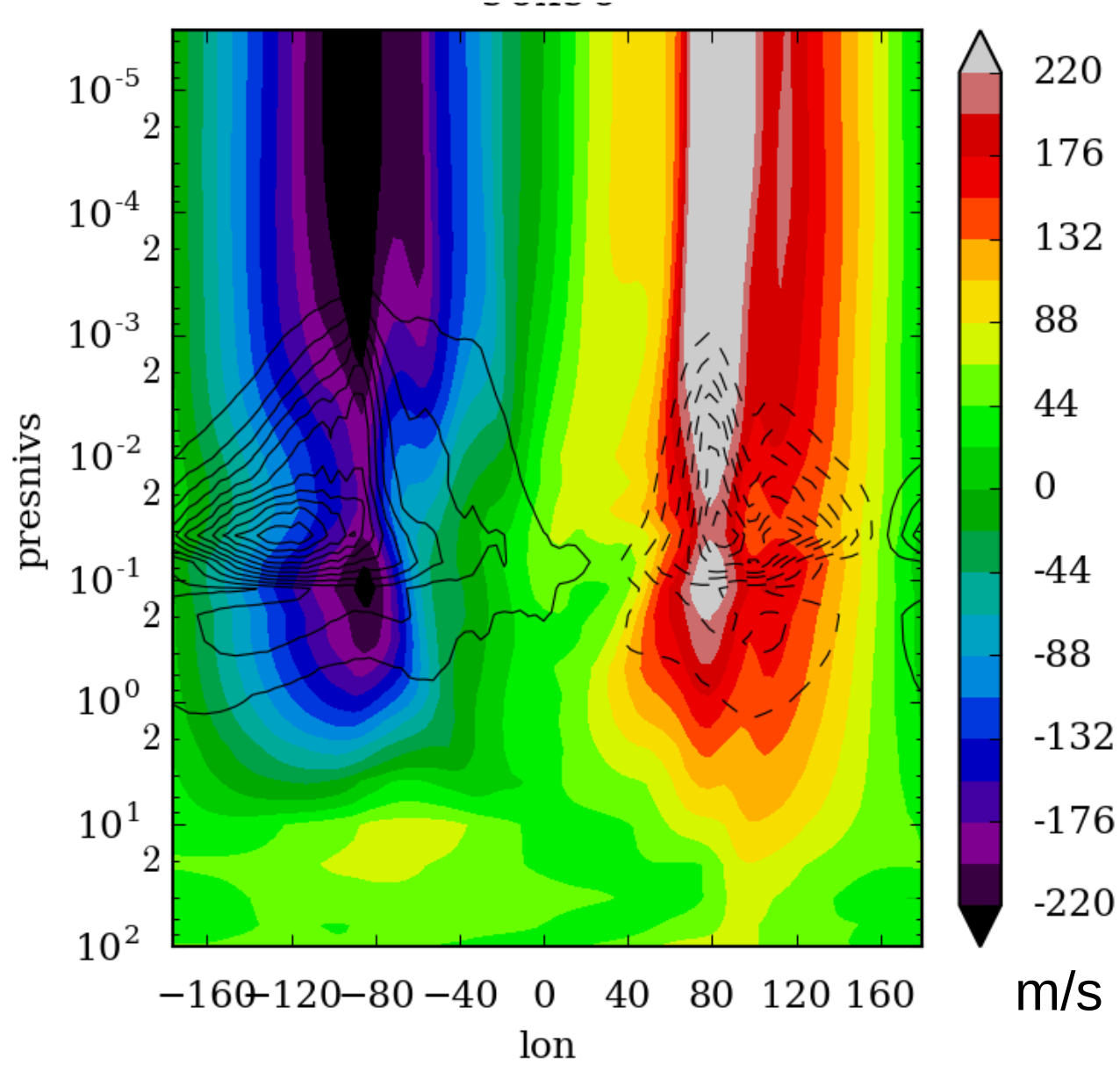

Average [40N-40S]

Colors : zonal wind

Contours : acceleration due to non-orographic GW

Acceleration of zonal wind due to non-orographic gravity waves generated at cloud top 


\section{Stationary waves}

Topographic gravity waves parameterization

=> equatorial mountain waves develop in the afternoon and propagate above the clouds
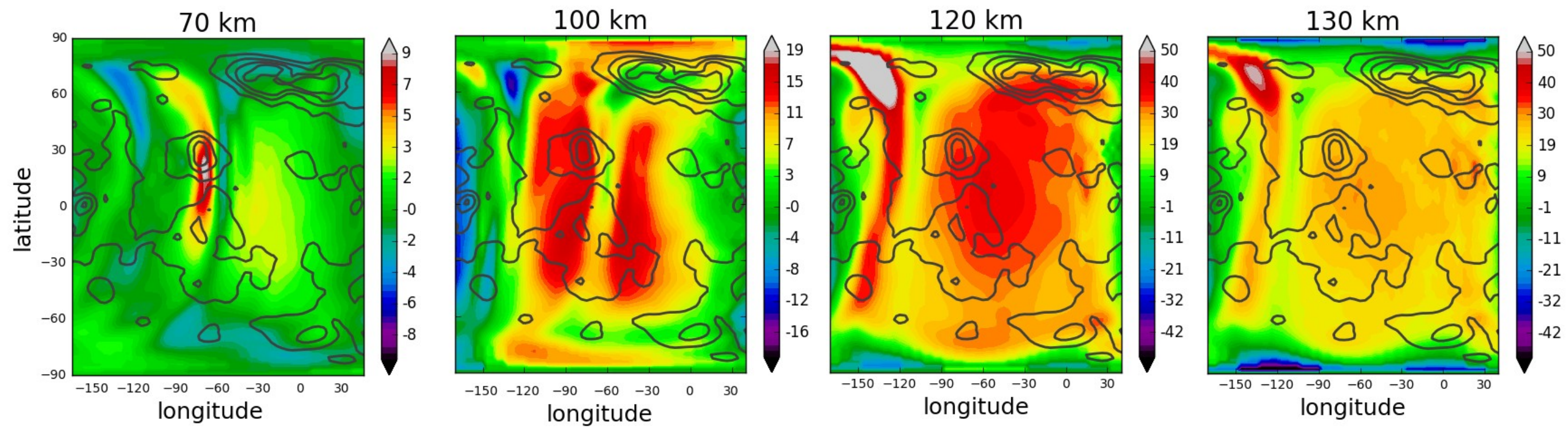

Vertical wind speeds $(\mathrm{cm} / \mathrm{s})$ 


\section{Conclusion}

The IPSL Venus GCM is a mature tool to study the upper atmosphere of

Venus and its variability.

- Variability of the descending/ascending winds

- Variability due to orographic and non-orographic gravity waves

Sensitivity of temperature and circulation to model parameters and to horizontal resolution still to be fully assessed.

\section{Open postdoctoral position at LMD}

Study of the upper atmosphere of Venus $=>$ starting in autumn 2020 (for 2 years)

ESA-funded project : Venus Climate Database (release : Sept. 2021)

Virtual meeting : wednesday May 6th, 18h-19h (CEST)

Presentation of the VCD, discussion, ideas and needs welcome !

contact sebastien.lebonnois@Imd.jussieu.fr for link 